Bartosz Piechaczek*, Grzegorz Gruszka*, Andrzej Pyc ${ }^{* *}$, Emanuele Iero ${ }^{* * *}$

\title{
UTILISATION OF PRESSURE FILTRATION USING FILTER PRESSES FOR THE DEWATERING OF THE FINEST PARTICLES OF MINERAL CONCENTRATES
}

\section{Introduction}

The most popular method of the beneficiation of the finest particles of useful minerals with the size $1-0$ is froth flotation. It is a common knowledge that the concentrate resulting from this process requires dewatering and then additional drying, e.g. thermal, in order to meet customers' requirements. There are a number of methods used in the dewatering of mineral concentrates. The most popular technologies utilised at coal processing plants in Poland are: vacuum filters, e.g. disc type, screen-bowl decanter centrifuges and filter presses. The focus of this paper is on the latter technology which in many respects overshadows the former two.

\section{Advantages of filter presses}

Thanks to the possibility to add complementary technologies horizontal filter presses can offer the most efficient dewatering of the finest mineral particles - offering low residual moisture of the filter cake, high productivity, recovery of nearly $100 \%$ of solids from the suspension which results in the obtaining of clean filtrate which then can be returned to the water-slurry circuit as industrial water for further reuse.

\footnotetext{
* PROREM sp. z o.o.

** Biuro Projektów PROREM Sp. z o.o.

**** Bilfinger Water Technologies Srl
} 


\section{Types of filter presses}

Horizontal filter presses can be divided into different types - according to different criteria which are used to make the distinction:

- according to filter plates used:

- chamber,

- membrane,

- mixed (chamber and membrane plates alternately),

- according to the method of filter plate installation:

- side bar,

- upper beam,

- according to the level of automation:

- manual,

- semi-automatic,

- automatic,

- according to the number of hydraulic jacks closing the plate pack:

- single-jack,

- multi-jack (e.g. 2 or 4),

- according to the jack operation method:

- push-to-close,

- pull-to-close.

\section{Complementary technologies}

Horizontal filter presses can also be equipped with additional technologies whose task is to offer a specific feature - required in the given application:

- membrane squeezing:

- with compressed air,

- with water,

- cake blowing,

- cake washing.

\section{Additional equipment}

In order to optimise the filtration process, to improve the quality of the cake and/or filtrate, as well as for other technological reasons filter presses can be equipped with:

- filter press feeding system from both sides,

- high pressure and/or low pressure filter cloth washing system, 
- filter press weighing system using load cells,

- sliding platform for plate and cloth maintenance,

- plate extractor,

- automatic lubricating system,

- drip tray.

\section{Jas-Mos coal mine — case study}

\subsection{Introduction}

At the turn of the century at coal mines now being part of the biggest producer of coke in Europe - Jastrzębska Spółka Węglowa SA for the dewatering of flotation concentrate screen-bowl decanter centrifuges were being introduced replacing vacuum disc filters which had been used until then. Unfortunately the operation of the centrifuges in industrial applications has revealed a number of drawbacks of this particular technology. The most significant are:

- high energy costs,

- high maintenance and running costs,

- necessity to use flocculants,

- loss of coal particles below $25 \mu \mathrm{m}$ together with the effluent.

The latter flaw caused the closed water-slurry circuits at processing plants to fill with the fine grains present in the effluent from the bowl part of the centrifuges - the so-called sediment, which made the correct operation of these plants impossible. Coal mines employed various methods to cope with this fine product. Sediment at Jas-Mos coal mine had been mixed with other products and then pumped underground for backfilling. The coal mine, however, aware of the imperfection of this solution had kept looking for a technology, which would make it possible to recover these fine particles, which had so far been lost irretrievably, while at the same time, clean up the water-slurry circuit of the processing plant. After the thorough evaluation of various concepts, it was decided that the optimum solution would be the installation of a sediment dewatering system, based on a filter press - a system proposed by PROREM.

\subsection{Investment project}

In November 2009 the mine management decided to launch formal tender proceedings aimed at an investment project entitled 'Construction of a system for recovery of solids from water-slurry suspension containing only particles below $25 \mu \mathrm{m}$ for JSW SA KWK JasMos'. The general contractor of the project decided to employ Biuro Projektów PROREM to design the new system, and PROREM to supply the filter press with all necessary ancillaries. PROREM recommended a filter press manufactured by an Italian company called DIEMME Filtration (now Bilfinger Water Technologies) - a global leader in the manufacture of specialised filter presses. The high quality of the machines coupled with a professional 
approach to the sizing of the best filter press for this particular application resulted in DIEMME Filtration beating a number of competitors - including some of the biggest names in the filter press sector.

The scope of the project included:

- designing a technology enabling the recovery of solids from water-slurry suspension containing only particles below $25 \mu \mathrm{m}$. Technological requirements for the system:

- productivity: minimum $8 \mathrm{Mg} / \mathrm{h}$ of dry solids,

- recovery of solids: minimum $98 \%$,

- $W_{e x}$ residual moisture content in the filter cake: maximum $28 \%$,

- drawing up an environmental impact report and a multi-discipline design of the new system,

— inclusion of the designed system into the existing technological system of the processing plant so that the operating system does not interfere with the coal beneficiation process and the water-slurry system,

- supply of the components of the system,

- installation of the designed system components,

- carrying out a start-up of the system and test-run until reaching the required performance parameters,

- providing at least 24 months of warranty for the components of the system,

- training for the coal mine personnel in terms of operation and maintenance of the machines.

\subsection{Laboratory tests and concept}

The process of drawing up the final technological solution started with taking a representative sample of a thickened sediment in order to carry out laboratory filtration tests. The sample received from the investor had the following physical-chemical characteristics.

TABLE 1

Physical-chemical characteristic of the sample (source: own materials)

\begin{tabular}{|l|c|}
\hline \multicolumn{1}{|c|}{ Parameter } & Value \\
\hline Temperature, $\left[{ }^{\circ} \mathrm{C}\right]$ & 20 \\
\hline $\mathrm{pH}$ & 7.8 \\
\hline Specific weight, $\left[\mathrm{kg} / \mathrm{dm}^{3}\right]$ & 1.00 \\
\hline Solid concentration, $[\mathrm{g} / \mathrm{l}]$ & 131 \\
\hline $\mathrm{CST}_{18},[\mathrm{sec}]$ & 13.4 \\
\hline Conductivity, $[\mathrm{mS} / \mathrm{cm}]$ & 6.5 \\
\hline Colour & black \\
\hline
\end{tabular}


TABLE 2

Particle-size distribution of the sample (source: own materials)

\begin{tabular}{|c|c|c|c|}
\hline $\begin{array}{c}\text { Size low, } \\
{[\mu \mathrm{m}]}\end{array}$ & $\begin{array}{l}\text { In, } \\
{[\%]}\end{array}$ & $\begin{array}{c}\text { Size high, } \\
{[\mu \mathrm{m}]}\end{array}$ & $\begin{array}{c}\text { Under, } \\
{[\%]}\end{array}$ \\
\hline 0.05 & 0.02 & 0.06 & 0.02 \\
\hline 0.06 & 0.04 & 0.07 & 0.05 \\
\hline 0.07 & 0.06 & 0.08 & 0.12 \\
\hline 0.08 & 0.11 & 0.09 & 0.22 \\
\hline 0.09 & 0.17 & 0.11 & 0.40 \\
\hline 0.11 & 0.27 & 0.13 & 0.66 \\
\hline 0.13 & 0.41 & 0.15 & 1.07 \\
\hline 0.15 & 0.60 & 0.17 & 1.68 \\
\hline 0.17 & 0.85 & 0.20 & 2.53 \\
\hline 0.20 & 1.15 & 0.23 & 3.68 \\
\hline 0.23 & 1.45 & 0.27 & 5.14 \\
\hline 0.27 & 1.66 & 0.31 & 6.79 \\
\hline 0.31 & 1.68 & 0.36 & 8.47 \\
\hline 0.36 & 1.58 & 0.42 & 10.05 \\
\hline 0.42 & 1.46 & 0.49 & 11.51 \\
\hline 0.49 & 1.32 & 0.58 & 12.83 \\
\hline 0.58 & 1.14 & 0.67 & 13.96 \\
\hline 0.67 & 1.00 & 0.78 & 14.97 \\
\hline 0.78 & 0.74 & 0.91 & 15.71 \\
\hline 0.91 & 0.75 & 1.06 & 16.46 \\
\hline 1.06 & 0.80 & 1.24 & 17.26 \\
\hline 1.24 & 0.91 & 1.44 & 18.17 \\
\hline 1.44 & 1.05 & 1.68 & 19.22 \\
\hline 1.68 & 1.23 & 1.95 & 20.45 \\
\hline 1.95 & 1.47 & 2.28 & 21.92 \\
\hline 2.28 & 1.76 & 2.65 & 23.68 \\
\hline 2.65 & 2.14 & 3.09 & 25.83 \\
\hline 3.09 & 2.63 & 3.60 & 28.46 \\
\hline 3.60 & 3.23 & 4.19 & 31.68 \\
\hline 4.19 & 3.90 & 4.88 & 35.59 \\
\hline 4.88 & 4.62 & 5.69 & 40.20 \\
\hline
\end{tabular}

\begin{tabular}{|c|c|c|c|}
\hline $\begin{array}{c}\text { Size low, } \\
{[\mu \mathrm{m}]}\end{array}$ & $\begin{array}{l}\text { In, } \\
{[\%]}\end{array}$ & $\begin{array}{c}\text { Size high, } \\
\quad[\mu \mathrm{m}]\end{array}$ & $\begin{array}{c}\text { Under, } \\
{[\%]}\end{array}$ \\
\hline 5.69 & 5.30 & 6.63 & 45.50 \\
\hline 6.63 & 5.89 & 7.72 & 51.39 \\
\hline 7.72 & 6.33 & 9.00 & 57.72 \\
\hline 9.00 & 6.56 & 10.48 & 64.28 \\
\hline 10.48 & 6.58 & 12.21 & 70.86 \\
\hline 12.21 & 6.45 & 14.22 & 77.31 \\
\hline 14.22 & 5.83 & 16.57 & 83.15 \\
\hline 16.57 & 5.01 & 19.31 & 88.16 \\
\hline 19.31 & 4.08 & 22.49 & 92.24 \\
\hline 22.49 & 3.18 & 26.20 & 95.41 \\
\hline 26.20 & 2.32 & 30.53 & 97.73 \\
\hline 30.53 & 1.51 & 35.56 & 99.23 \\
\hline 35.56 & 0.77 & 41.43 & 100.00 \\
\hline 41.43 & 0.00 & 48.27 & 100.00 \\
\hline 48.27 & 0.00 & 56.23 & 100.00 \\
\hline 56.23 & 0.00 & 65.51 & 100.00 \\
\hline 65.51 & 0.00 & 76.32 & 100.00 \\
\hline 76.32 & 0.00 & 88.91 & 100.00 \\
\hline 88.91 & 0.00 & 103.58 & 100.00 \\
\hline 103.58 & 0.00 & 120.67 & 100.00 \\
\hline 120.67 & 0.00 & 140.58 & 100.00 \\
\hline 140.58 & 0.00 & 163.77 & 100.00 \\
\hline 163.77 & 0.00 & 190.80 & 100.00 \\
\hline 190.80 & 0.00 & 222.28 & 100.00 \\
\hline 222.28 & 0.00 & 258.95 & 100.00 \\
\hline 258.95 & 0.00 & 301.68 & 100.00 \\
\hline 301.68 & 0.00 & 351.46 & 100.00 \\
\hline 351.46 & 0.00 & 409.45 & 100.00 \\
\hline 409.45 & 0.00 & 477.01 & 100.00 \\
\hline 477.01 & 0.00 & 555.71 & 100.00 \\
\hline
\end{tabular}




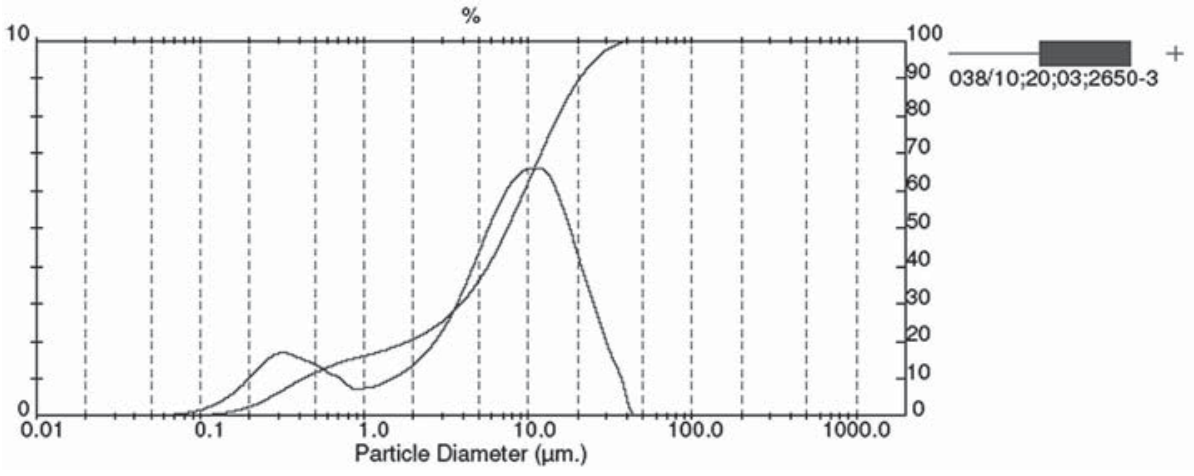

Fig. 1. Graphic representation of the particle-size distribution of the sample (source: own materials)
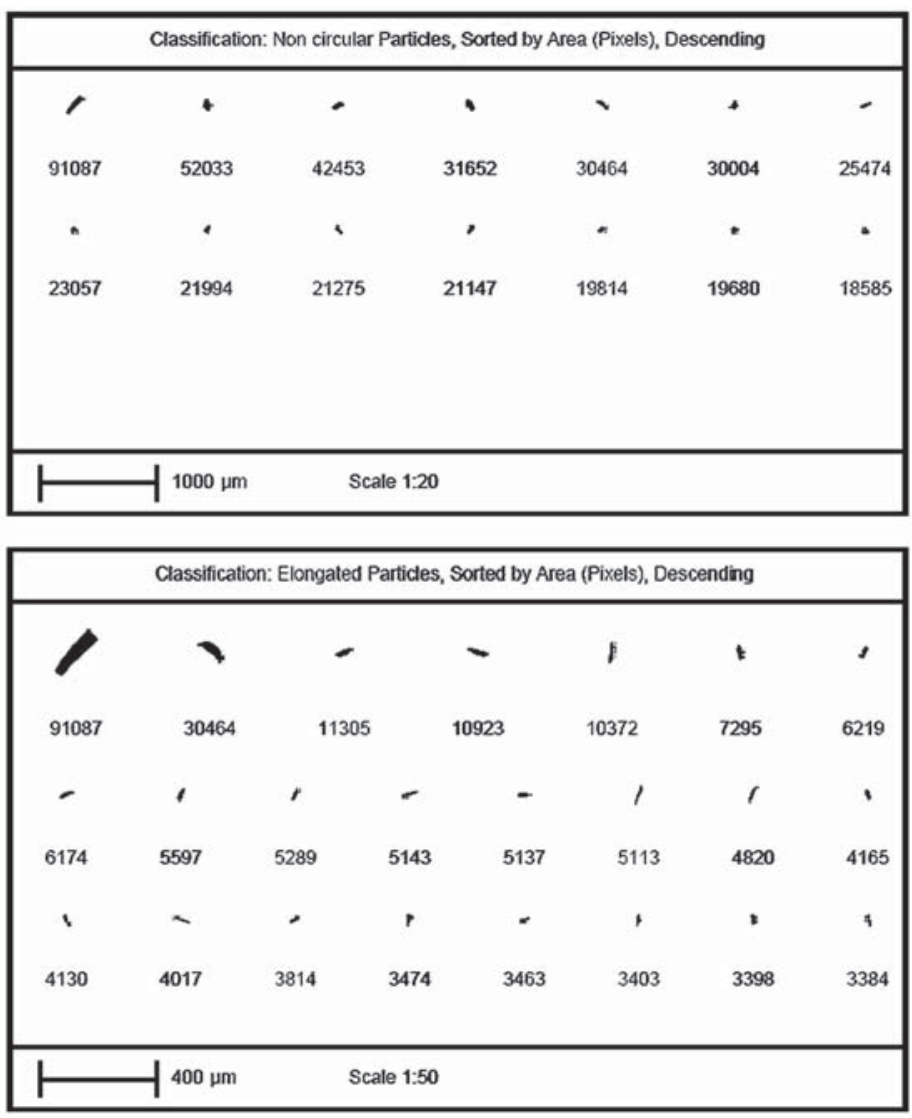

Fig. 2. Morphological particle-size distribution of the sample (source: own materials) 
The dimensional particle-size analysis carried out confirmed that the content of grains bigger than $25 \mu \mathrm{m}$ in the thickened sediment is marginal — approximately $6 \%$.

A morphological analysis was carried out in order to define the physical properties of solids, as well as inspect how these solids influence the filtration process, residual moisture and the compactness of the cake. As well as this, the analysis assisted with the prediction and prevention of phenomenon such as thixotropy, abrasiveness of the slurry and improving the efficiency of washing and other technological parameters.

Four tests were carried out on the sample provided by the investor:

- test with membrane squeezing using compressed air at 15 bar, without cake blowing,

- test with membrane squeezing using compressed air at 15 bar, with cake blowing using compressed air at 3 bar,

- test with membrane squeezing using compressed air at 15 bar, with cake blowing using compressed air at 5 bar,

— test with membrane squeezing using compressed air at 15 bar, with cake blowing using compressed air at 6 bar.

TABLE 3

Laboratory filtration test results (source: own materials)

\begin{tabular}{|c|c|c|c|c|}
\hline Test no. & 1 & 2 & 3 & 4 \\
\hline Filtration area, $\left[\mathrm{m}^{2}\right]$ & \multicolumn{4}{|c|}{0.008} \\
\hline Temperature, $\left[{ }^{\circ} \mathrm{C}\right]$ & \multicolumn{4}{|c|}{ ambient } \\
\hline Feeding pressure, $[\mathrm{bar}]$ & \multicolumn{4}{|c|}{7} \\
\hline Cake blowing pressure, [bar] & - & 3 & 5 & 6 \\
\hline Membrane squeezing pressure, [bar] & \multicolumn{4}{|c|}{15} \\
\hline Filtrate quality & \multicolumn{4}{|c|}{ limpid } \\
\hline Cake quality & \multicolumn{2}{|c|}{ compact } & \multicolumn{2}{|c|}{ compact, friable } \\
\hline Dry solids, [\%] & 64.4 & 67.8 & 69.9 & 72 \\
\hline $\mathrm{W}_{\mathrm{ex}}$ residual moisture, $[\%]$ & 35.6 & 32.2 & 30.1 & 28 \\
\hline
\end{tabular}

The results of filtration tests showed that in order to meet a required residual moisture in the cake of not more than $28 \%$ at the productivity of minimum $8 \mathrm{Mg} / \mathrm{h}$ of dry solids in the process of the dewatering of thickened coal sediment it is necessary to use a filter press equipped with the following technologies:

- mixed plate pack,

- membrane squeezing with compressed air,

- cake blowing with compressed air at 6 bar,

- automatic filter cloth washing system. 
On the grounds of these filtration tests and the investor's requirements regarding the productivity of the dewatering system along with the estimated plant working time, the decision was made to install a model GHT 1500.P7 filter press with the following features:

- number of chamber plates: 41 ,

- number of membrane plates: 40 ,

- chamber thickness: $50 \mathrm{~mm}$,

- filter press feeding system from both sides,

- power cabinet with a PLC and a touch control panel,

- drip tray,

- automatic filter cloth washing system,

- fixed perimeter barrier,

- photocell barrier on one side of the filter press,

- sliding platform for cloths and plates maintenance,

- centrifugal feeding pump,

- rotary screw compressor for cake blowing with a buffer tank,

- piston compressor for membrane squeezing with a buffer tank.

\subsection{Results}

One of the investor's requirements was to carry out a start-up and test-run of the system until the required performance parameters had been reached. The required parameters were achieved in a very short time.

Moreover, thanks to a very careful sizing of the machine with sufficient tolerance, the results obtained significantly exceeded the investor's requirements, which gave the end-user a certain degree of flexibility, regarding the set-up of the machine making it possible either to lower the residual moisture in the cake or increase the productivity of the system. The table below shows the results of industrial filtration tests on the actual products coming from the newly installed filter press for the dewatering of coal sediment, carried out between $22^{\text {nd }}$ and $23^{\text {rd }}$ September 2011.

The drawing below shows a simplified P\&I of the new system for the recovery of solids from water-slurry suspension containing only particles below $25 \mu \mathrm{m}$ installed at Jas-Mos coal mine.

TABLE 4

Industrial filtration test results (source: own materials)

\begin{tabular}{|l|c|c|c|c|c|c|c|c|}
\hline \multicolumn{1}{|c|}{ Test no. } & $\mathbf{1}$ & $\mathbf{2}$ & $\mathbf{3}$ & $\mathbf{4}$ & $\mathbf{5}$ & $\mathbf{6}$ & $\mathbf{7}$ & $\mathbf{8}$ \\
\hline $\mathrm{W}_{\mathrm{ex}}$ residual moisture in the cake, $[\%]$ & 22.43 & 23.92 & 23.85 & 23.42 & 23.48 & 22.44 & 23.39 & 19.50 \\
\hline Productivity of dry solids, $[\mathrm{Mg} / \mathrm{h}]$ & 9.79 & 9.69 & 9.55 & 9.56 & 9.82 & 10.05 & 10.73 & 7.76 \\
\hline Total filtration cycle time, $[\mathrm{min}]$ & 25.20 & 25.20 & 25.20 & 25.00 & 25.00 & 25.00 & 22.70 & 31.40 \\
\hline
\end{tabular}




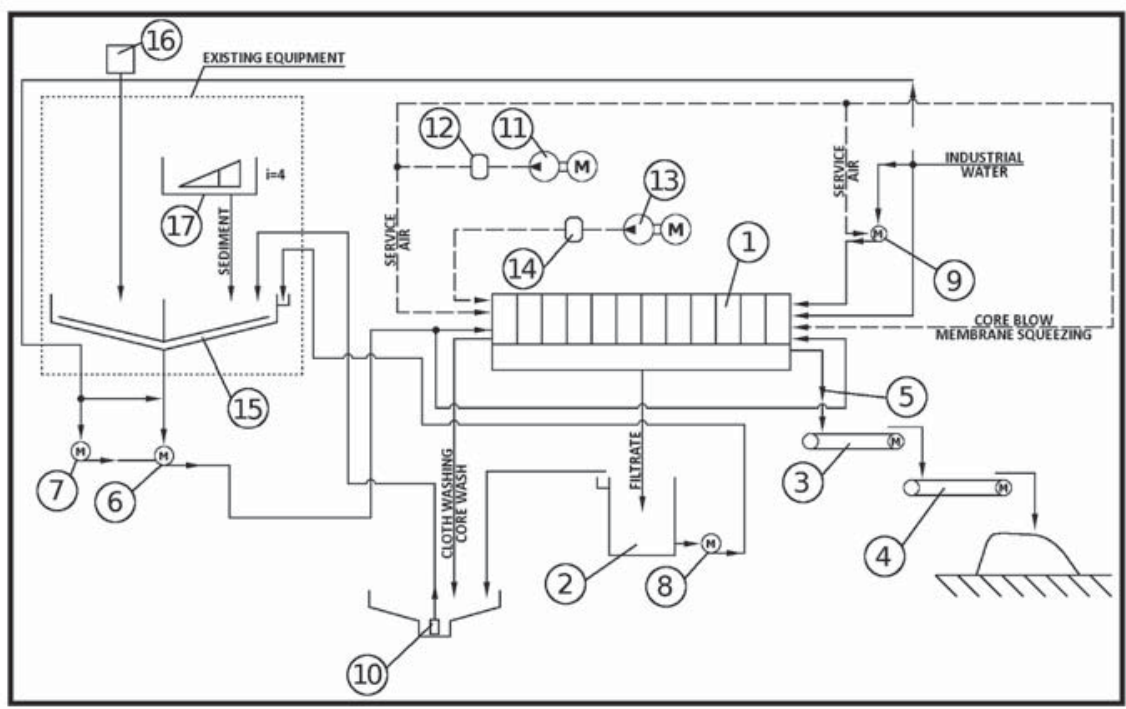

Fig. 3. P\&I of the new system (source: own materials):

1 - Filter press model GHT 1500.P7, 2 - Filtrate tank, 3 - Belt conveyor, 4 - Belt conveyor,

5 - Cake collection chute, 6 - Feeding pump, 7 - Sealing water pump, 8 - Filtrate pump,

9 - Cloth washing pump, 10 - Sump pump, 11 - Piston compressor, 12 - Buffer tank,

13 - Screw compressor, 14 - Buffer tank, 15 - Thickener, 16 - Flocculant preparation unit,

17 - Screen-bowl decanter centrifuges

\section{Summary}

The aim of the investment project at Jas-Mos coal mine was to recover fine particles of coking coal from the sediment and to reach such quality parameters which would enable the product to become saleable by mixing it with other coal products.

The project was successfully concluded in October 2011 and the new system was officially handed over to the investor. Filtration tests carried out both by the investor and by an independent laboratory confirmed that the required performance parameters had been achieved.

In order to make a full and thorough evaluation of the project it is important to bear in mind that thanks to the new system the coal mine has benefitted from:

- additional amounts of saleable product which provided the investor with the return on investment within just a few months,

- fully closed, clear water-slurry circuit,

- reduction of the negative environmental impact,

- state-of-the-art system which should be utilised at all processing plants using screenbowl decanter centrifuges. 


\section{REFERENCES}

[1] PROREM sp. z o.o. own materials

[2] Biuro Projektów PROREM sp. z o.o. own materials

[3] DIEMME Filtration Srl own materials. 